\title{
Incidence of H1N1 in pediatric population in a tertiary care hospital in Bangalore
}

\author{
Mahantesh $\mathbf{S}^{1}$, Manasa $\mathbf{S}^{2}$ \\ ${ }^{1}$ Dr. Mahantesh. S, Associate Professor, ${ }^{2}$ Dr. Manasa. S, Scientist B, both authors are affiliated with Department of \\ Microbiology, Indira Gandhi Institute of Child Health, Bangalore, Karnataka, India.
}

Address for Correspondence: Dr. Manasa. S, Scientist B, Department of Microbiology, Indhira Ghandhi Institute of Child Health, Bangalore, Email: manasabharadwaj86@gmail.com

\begin{abstract}
Objectives: Influenza viruses continue to be a major health threat in both endemic and pandemic forms. The rapid, continuous, and unpredictable nature of influenza viral evolution makes vaccine strategies and pandemic planning difficult. In elderly, infants and in people with chronic diseases, influenza is associated with high mortality. As there are very limited studies relating to Influenza A H1N1 and its epidemiology in the pediatric population, this study was done to study the clinical and epidemiological profile of patients found positive for Influenza A H1N1 in pediatric population in a tertiary care hospital in Bangalore. Materials and methods: This is a retrospective study done over a period of 6 months from January 2017 to June 2017. The study population included all the suspected patients tested for Influenza A H1N1 by real-time RT-PCR. Results: Total of 89 patients were tested for Influenza A H1N1 out of which 31(34.8\%) were positive. The most common symptoms were fever (87.6\%), cough $(49.77 \%)$, sore throat $(27 \%)$ and breathlessness (23.9\%). Maximum cases were detected in the 0-5 years age group in that $19(61.2 \%)$ were positive, followed by $15-18$ yrs in which 23(25.8\%) were tested in which 9(29.03\%) were positive. Influenza A H1N1 resulted in death of 3(3.3\%) of the total admitted suspected H1N1 cases in our hospital. Conclusion: On the basis of these findings, it can be concluded that prevalence of Influenza A H1N1 is high in children with the age group of 0-5yrs. The age shift of severe influenza A (H1N1) towards younger children may be explained by increasing immunity in the older pediatric population.
\end{abstract}

Key words: Incidence; Influenza A; H1N1.

\section{Introduction}

Influenza viruses are among the most common causes of human respiratory infections [1] and among the most significant because they cause high morbidity and mortality. Influenza virus is a new virus which came up in late April 2009 in Kerala and probably originated in the pig farms in Mexico [1-4]. Hence, it was called swine flu. Inside the pigs a genetic reassortment occurred to the usual influenza viruses resulting in the new H1N1 virus. The virus was introduced to human beings and thereafter spread from man to man. H1N1 pandemic had its significantly great impact in India from April 2009 to August 2010 [2-5].

Influenza is an acute respiratory disease characterized in its full form by the sudden onset of high fever,

Manuscript received: $20^{\text {th }}$ July 2017

Reviewed: $30^{\text {th }}$ July 2017

Author Corrected: $7^{\text {th }}$ August 2017

Accepted for Publication: $14^{\text {th }}$ August 2017 coryza, cough, headache, prostration, malaise, and inflammation of the upper respiratory tree and trachea. In most cases, pneumonic involvement is not clinically prominent. Acute symptoms and fever often persist for 7 to 10 days [6]. In the elderly, in infants, and in people with chronic diseases, influenza is associated with especially high mortality. As there are very limited studies relating to Influenza A $\mathrm{H} 1 \mathrm{~N} 1$ and its epidemiology in the pediatric population, this study was done to study the clinical and epidemiological profile of patients found positive for Influenza A H1N1 in pediatric population in a tertiary care hospital in Bangalore.

\section{Materials and Methods}

Source of Data: This is a retrospective study done over a period of 6months from January 2017 to June 2017. 


\section{Research Article}

The study will be conducted in the department of Microbiology, Indhiraghandhi institute of child health. The study population included all the suspected pediatric patients tested for Influenza A H1N1.

Inclusion criteria: All the suspected pediatric patients having H1N1 below 18ys were included in the study

Exclusion Criteria: Patients above 18yrs were excluded, and also patients positive for HIV and HBsAg

Methodology: Because of viral shedding patterns, The following specimen was collected as soon as possible after illness onset: nasopharyngeal swab, nasal aspirate or a combined nasopharyngeal swab with oropharyngeal swab. If these specimens cannot be collected, a nasal swab or oropharyngeal swab is acceptable. For patients who are intubated, an endotracheal aspirate was collected. Bronchoalveolar lavage (BAL) and sputum specimens were also accepted. Specimens was placed into sterile viral transport media (VTM) and immediately placed on ice or cold packs or at $4{ }^{\circ} \mathrm{C}$ (refrigerator) for transport to the laboratory. Recommended infection control guidelines was followed for persons collecting clinical specimens in clinics and other clinical settings. Swab specimens was collected using swabs with a synthetic tip and a plastic shaft. The swab specimen collection vials contained $1-3 \mathrm{ml}$ of viral transport medium (containing, protein stabilizer, antibiotics to discourage bacterial and fungal growth, and buffer solution). All respiratory specimens was kept at $4^{\circ} \mathrm{C}$ for no longer than 4 days.

Clinical specimens was shipped on wet ice or cold packs in appropriate packaging to the NIMHANS. A Real-time RT-PCR was done in NIMHANS Currently, novel influenza A (H1N1) virus will test positive for influenza $\mathrm{A}$ and negative for $\mathrm{H} 1$ and $\mathrm{H} 3$ by real-time RT-PCR. If reactivity of real-time RT-PCR for influenza $\mathrm{A}$ is strong (e.g. $\mathrm{Ct}<30$ ) it is more suggestive of a novel influenza $\mathrm{A}$ (H1N1) virus.

\section{Results}

The results were collected from NIMHANS and the data was compiled. A total of 89patients were tested for Influenza A H1N1 by real-time RT-PCR, out of which31 (34.8\%) were positive. In the total of 89 suspected patients, 38 (42.6\%) were males in which $8(25.8 \%)$ were positives and $51(57.3 \%)$ were female children in which $13(41.9 \%)$ were positives.
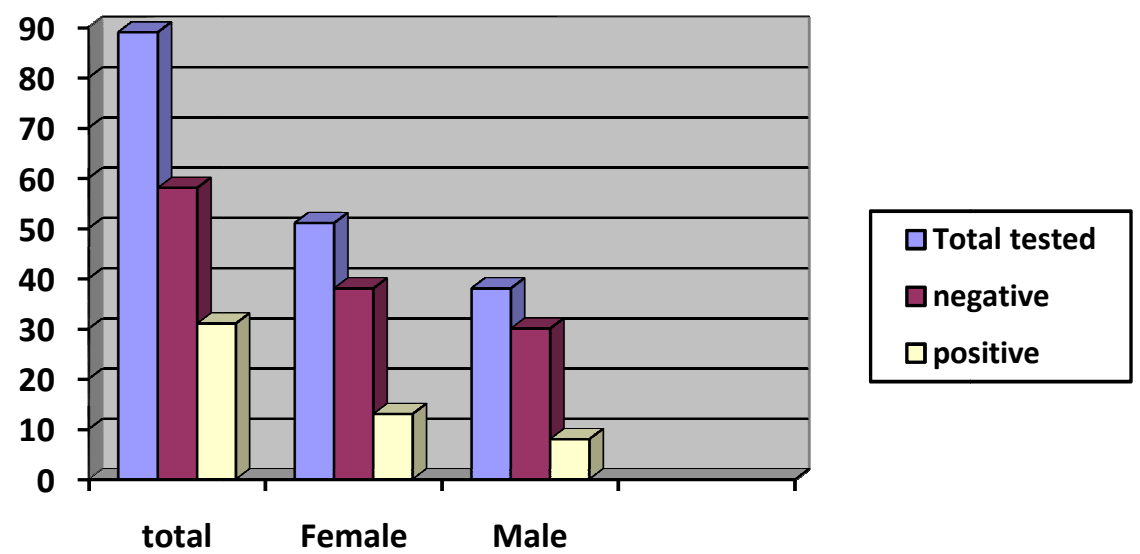

Fig-1: Distribution of positive and negative patients based on sex of the patients

Table-1: Distribution of the patients based on their age.

\begin{tabular}{|c|c|c|c|}
\hline Age group & Total suspected cases & Positives & Negatives \\
\hline $0-5 y r s$ & $42(47.1 \%)$ & $19(45.2 \%)$ & $23(54.7 \%)$ \\
\hline $5-10 y r s$ & $18(20.2 \%)$ & $2(11.1 \%)$ & $16(88.8 \%)$ \\
\hline $10-15 y r s$ & $6(6.7 \%)$ & $1(16.6 \%)$ & $5(83.3 \%)$ \\
\hline $15-18 y r s$ & $23(25.8 \%)$ & $9(39.1 \%)$ & $14(60.8 \%)$ \\
\hline
\end{tabular}


Research Article

The total number of suspected H1N1 cases who were tested were maximum in the age group of $0-5 \mathrm{yrs}$ i.e $42(47.1 \%)$ followed by $15-18$ yrs, which had $23(25.8 \%)$ suspected patients with $9(39.1 \%)$ positive cases. The highest number of positive cases were also in the age group, 0-5yrs i.e 19(45.2\%).

The patients presented with many symptoms. The most common symptoms were fever $(89.8 \%)$, cough $(59.7 \%)$, sore throat $(37 \%)$ and breathlessness $(20.9 \%)$.

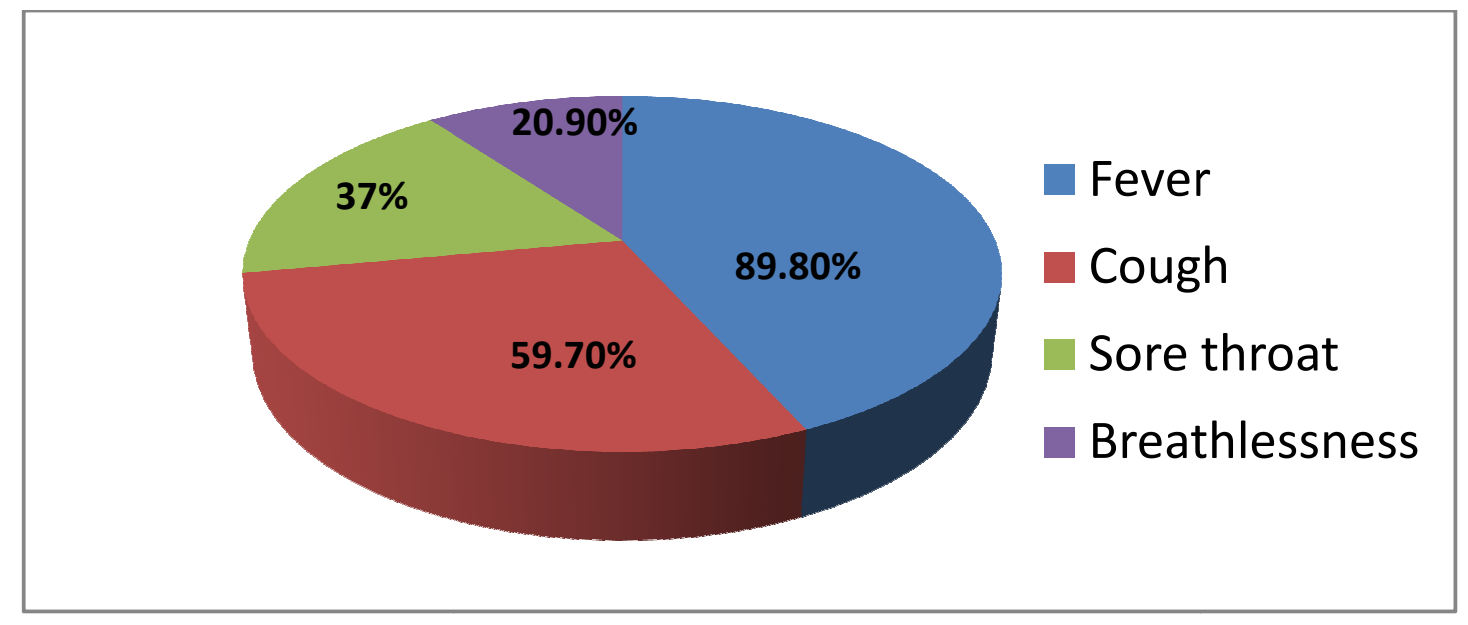

Fig-2: Distribution of symptoms with which the patient presented

Maximum cases were detected in the month April than any other month during this season. Influenza A H1N1 resulted in death of $3(3.3 \%)$ of the admitted cases, of which all the deaths occurred within $48 \mathrm{~h}$ of admission.

\section{Discussion}

Influenza is the one of the most significant acute upper respiratory tract infections. Influenza viruses cause a broad array of respiratory illnesses responsible for significant morbidity and mortality in children. Influenza viruses cause epidemic disease (influenza virus types $\mathrm{A}$ and $\mathrm{B}$ ) and sporadic disease (type C) in humans.

The word influenza may have been derived from the Latin word influo, which means "to flow in," indicating airborne transmission, or from the Italian word influence, which indicates influence of weather or an astrological influence. In addition to humans, influenza also infects a variety of animal species. Some of these influenza strains are species specific, but new strains of influenza may spread from other animal species to humans. The term avian influenza used in this context refers to zoonotic human infection with an influenza strain that primarily affects birds $[2,3]$.

Swine influenza refers to infections from strains derived from pigs. Influenza viruses are negative-sense, singlestrand RNA viruses that belong to the family Orthomyxoviridae. Human influenza viruses are divided into 3 major types: $\mathrm{A}, \mathrm{B}$, and $\mathrm{C}$.
Influenza type A viruses cause disease in humans and many animal species. Waterfowl (eg, ducks, geese) are the natural reservoir for type $\mathrm{A}$. In addition, in freshwater lakes, influenza A virus can stay alive for 4 days at $22^{\circ} \mathrm{C}$ and for more than a month at $0^{\circ} \mathrm{C}$.

Influenza type B viruses primarily cause disease in humans, particularly children. Infections with influenza type $\mathrm{C}$ viruses are rare [4,5].

Influenza viral RNA has 8 genetic elements. The RNA has a lipid envelope with 2 major antigenic components on its surface, hemagglutinin $(\mathrm{H})$ and neuraminidase $(\mathrm{N})$. These components enable the replication and subsequent release of the virus, leading to its spread. Influenza type A viruses also have ionic channel proteins, termed M2 proteins.

The $\mathrm{H}$ antigen is the major virulence determinant because these antigens help viral attachment to the cell. $\mathrm{H}$ proteins are divided into 16 types, whereas $\mathrm{N}$ proteins are divided into 9 types. $\mathrm{N}$ act on the sialic acid component of the cell, which enables viral detachment. Different subtypes of influenza viruses are identified based on the combinations of these antigenic structures, 
Research Article

with 144 combinations possible. For example, influenza A subtype $\mathrm{H} 3 \mathrm{~N} 2$ expresses hemagglutinin 3 and neuraminidase 2. Influenza A subtype $\mathrm{H} 5 \mathrm{~N} 1$, or avian influenza, has been found in chickens, ducks, and migratory fowl throughout Asia and is now spreading west through Europe and North Africa. It is highly virulent in humans but is poorly transmissible between humans [6].

Influenza and parainfluenza viruses (PIVs) are among the most common respiratory pathogens that affect infants and children worldwide. Infections and their complications are responsible for a significant number of hospitalizations and fatalities on a yearly basis. In most temperate climate countries, seasonal patterns of disease are observed. In warmer climates, disease can be observed year round. The fear of an influenza pandemic looms when new strains are discovered.

Recognition and prevention become pressing priorities. In recent years, a greater emphasis in preventing influenza through vaccination has emerged. Many health care systems have mandatory vaccinations programs for health care professionals. In addition, vaccination is now recommended for all persons 6 months or older. Available antiviral agents are effective not only as therapy but also as preventive agents Influenza is one of the most common vaccinepreventable viral diseases, with the highest morbidity reported for children and elderly patients $[7,8]$.

Influenza infections during childhood usually present as mild respiratory upper airway disease, but severe complications and fatalities also occur, especially in children less than 2 years of age and in children with underlying chronic conditions [8-13]. However, 40$50 \%$ of influenza-associated fatalities occur in previously healthy children $[10,14]$.

In our study a total of 89patients were tested for Influenza A H1N1 by real-time RT-PCR, out of which31 (34.8\%) were positive. In the total of 89 suspected patients, $38(42.6 \%)$ were males in which $8(25.8 \%)$ were positives and $51(57.3 \%)$ were female children in which 13 (41.9\%) were positives.

The age group which was affected more was 0-5yrs this is in concordance with a study done in turkey in which A total of 821 children with 2009 pandemic H1N1 were hospitalized. The majority of admitted children (56.9\%) were younger than $5 \mathrm{y}$ of age [15].
The signs and symptoms of influenza caused by pandemic $\mathrm{H} 1 \mathrm{~N} 1$ influenza $\mathrm{A}$ virus are similar to those of seasonal influenza, although gastrointestinal manifestations appear to be more common with pandemic $\mathrm{H} 1 \mathrm{~N} 1$ influenza.

Vomiting and diarrhoea have been reported more often with 2009 H1N1 influenza than with seasonal influenza [16].

Dawood et al mentioned that $25 \%$ of their patients had diarrhoea, and $25 \%$ had vomiting [17]. In another study, diarrhoea or vomiting was reported in $39 \%$ of patients, including $42 \%$ of children (i.e., patients under the age of 18 years) and $37 \%$ of adults (those $\geq 18$ years) [18]. The patients presented with many symptoms.

The most common symptoms were fever (89.8\%), cough $(59.7 \%)$, sore throat $(37 \%)$ and breathlessness $(20.9 \%)$. None of our patients had diarrhoea, but about half of them complained from vomiting.

Several severe clinical syndromes associated with influenza A 2009 H1N1 infection may be seen. Other unusual presentations of influenza $A\left[\mathrm{H}_{1} \mathrm{~N}_{1}\right]$ virus were conjunctivitis, earache, hematemesis, epistaxis, croup, apnoea, acute abdomen, altered mental state $[19,20]$.

A high index of suspicion, prompt treatment and mechanical ventilation had a role in reducing the mortality.

Two classes of antiviral agents are available for influenza: adamantanes (amantadine, rimantadine) and neuraminidase inhibitors (oseltamivir, zanamivir).

Adamantanes are M2 ion channel inhibitors. Because of resistance among influenza A viruses, use of adamantanes has not been recommended since the 2005-2006 influenza season.

Neuraminidase inhibitors inhibit the release of virus and its spread. Oseltamivir (Tamiflu) is commonly used for treatment and prophylaxis of influenza types A and B and is effective in treating avian influenza. Oseltamivir resistance has been rarely reported in pandemic $\mathrm{H} 1 \mathrm{~N} 1$ influenza virus and avian influenza A/H5N1 virus [21].

\section{Conclusion}

The major cause of death was viral bronchopneumonia and ARDS. A high index of suspicion, prompt 
treatment with Oseltamivir and mechanical ventilation had a role in reducing the mortality. The age shift of severe infection of Influenza A (H1N1) towards younger children may be explained by increasing immunity in the older pediatric population. The high incidence in pediatric population compile implementation of the current influenza vaccination.

Funding: Nil, Conflict of interest: None initiated, Permission from IRB: Yes

\section{References}

1. Taubenberger JK, Morens DM. Influenza: the once and future pandemic. Public Health Rep. 2010 Apr;125 Suppl 3:16-26.

2. Jones KE, Patel NG, Levy MA, Storeygard A, Balk D, Gittleman JL, Daszak P. Global trends in emerging infectious diseases. Nature. 2008 Feb 21;451(7181): 990-3. doi: 10.1038/nature06536.

3. Bhatt KN, Jethw SC, Bhadiyadar D, Patel D, Joshi K. Study of clinical profile in patients with H1N1 influenza in Surat district, June 2009 - March 2010. J Assoc Physicians India 2012;60:15-9.

4. Sharma R, Agarwal S, Mehta S, Nawal CL, Bhandari $\mathrm{S}$, Rathore $\mathrm{M}$, et al. Profiling the mortality due to influenza A (H1N1) pdm09 at a tertiary care hospital in Jaipur during the current season--January \& February 2015. J Assoc Physicians India 2015;63:36-9.

5. Nadkar MY, Subramanian S, Ingole N. H1N1 influenza: An update. JAPI 2009;57:454-8

6. Centers for Disease Control and Prevention (CDC). Update: influenza activity--United States and world wide, 1999-2000 season, and composition of the 200001 influenza vaccine. MMWR Morb Mortal Wkly Rep. 2000 May 5;49(17):375-81.

7. Heikkinen T. Influenza in children. Acta Paediatr. 2006 Jul;95(7):778-84.

8. Poehling KA, Edwards KM, Weinberg GA, Szilagyi $\mathrm{P}$, Staat MA, Iwane MK, Bridges CB, Grijalva CG, Zhu Y, Bernstein DI, Herrera G, Erdman D, Hall CB, Seither R, Griffin MR; New Vaccine Surveillance Network. The underrecognized burden of influenza in young children. N Engl J Med. 2006 Jul 6;355(1): 31-40.
9. Quach C, Piché-Walker L, Platt R, Moore D. Risk factors associated with severe influenza infections in childhood: implication for vaccine strategy. Pediatrics. 2003;112:197-201. doi: 10.1542/peds.112.3.e197.

10. Wong KK, Jain S, Blanton L, Dhara R, Brammer L, Fry AM, Finelli L. Influenza-associated pediatric deaths in the United States, 2004-2012. Pediatrics. 2013 Nov; 132 (5):796-804. doi: 10.1542/peds.2013-1493. Epub 2013 Oct 28.

11. Gill PJ, Ashdown HF, Wang K, Heneghan C, Roberts NW, Harnden A, et al. Identification of children at risk of influenza-related complications in primary and ambulatory care: a systematic review and meta-analysis. Lancet Respir Med. 2015;3:139-49. doi: 10.1016/S2213-2600(14)70252-8.

12. Ruf BR, Knuf M. The burden of seasonal and pandemic influenza in infants and children. Eur J Pediatr. 2014 Mar;173(3):265-76. doi: 10.1007/s00431013-2023-6. Epub 2013 May 10.

13. Neuzil KM, Wright PF, Mitchel EF, Jr, Griffin MR. The burden of influenza illness in children with asthma and other chronic medical conditions. J Pediatr. 2000;137 :856-64. doi: 10.1067/mpd.2000.110445.

14. Louie JK, Schechter R, Honarmand S, Guevara H, Shoemaker TR, Madrigal NY, et al. Severe paediatric influenza in California, 2003-2005: implications for immunization recommendations. Pediatrics. 2006; 117 : e610-8. doi: 10.1542/peds.2005-1373.

15. Çiftçi E, Tuygun N, Özdemir H, Tezer H, Şensoy G, Devrim I et al .Clinical and epidemiological features of Turkish children with 2009 pandemic influenza A (H1N1) infection: experience from multiple tertiary paediatric centres in Turkey. 2009-2011Scand J Infect Dis. 2011 Dec; 43 (11-12):923-9. doi: 10.3109/ 00365548. 2011-598872.

16. Fitzgerald DA. Human swine influenza A [H1N1]: practical advice for clinicians early in the pandemic. Paediatr Respir Rev. 2009 Sep;10(3):154-8. doi: 10. 1016 /j. prrv.2009.06.005. Epub 2009 Jul 16.

17. Novel Swine-Origin Influenza A (H1N1) Virus Investigation Team, Dawood FS, Jain S, Finelli L, Shaw MW, Lindstrom S, Garten RJ, Gubareva LV, Xu $\mathrm{X}$, Bridges CB, Uyeki TM. Emergence of a novel 
swine-origin influenza A (H1N1) virus in humans. N Engl J Med. 2009 Jun 18;360(25):2605-15. doi: 10. 1056 / NEJMoa0903810. Epub 2009 May 7.

18. Witkop CT, Duffy MR, Macias EA, Gibbons TF, Escobar JD, Burwell KN, Knight KK. Novel Influenza A (H1N1) outbreak at the U.S. Air Force Academy: epidemiology and viral shedding duration. Am J Prev Med. 2010 Feb;38(2):121-6. doi: 10.1016/j.amepre. 2009. 10.005. Epub 2009 Oct 21.
19. Hackett S, Hill L, Patel J, Ratnaraja N, Ifeyinwa A, Farooqi M, Nusgen U, Debenham P, Gandhi D, Makwana N, Smit E, Welch S. Clinical characteristics of paediatric $\mathrm{H} 1 \mathrm{~N} 1$ admissions in Birmingham, UK. Lancet. 2009 Aug 22; 374 (9690):605. doi: 10.1016/ S0140-6736(09)61511-7.

20. Hayden FG, Gubareva LV, Monto AS, Klein TC, Elliot MJ, Hammond JM, et al. Inhaled zanamivir for the prevention of influenza in families. Zanamivir Family Study Group. N Engl J Med. 2000 Nov 2. 343 (18): 1282-9.

\section{How to cite this article?}

Mahantesh S, Manasa S. Incidence of H1N1 in pediatric population in a tertiary care hospital in Bangalore. Trop J Path Micro 2017;3(3):266-271.doi: 10.17511/jopm.2017.i3.06. 